UNICE - ENSINO SUPERIOR

IESF - INSTITUTO DE ENSINO SUPERIOR DE FORTALEZA

PÓS-GRADUAÇÃO EM GERENCIAMENTO DE PROJETOS

\title{
A TECNOLOGIA DA INFORMAÇÃO NOS ESCRITÓRIOS DE ADVOCACIA
}

ANTÔNIO JÚNIOR DA SILVA MAIA

Fortaleza - Ceará

2019.2 


\section{A TECNOLOGIA DA INFORMAÇÃO NOS ESCRITÓRIOS DE ADVOCACIA}

Artigo Científico apresentado à UNICE - Ensino Superior / IESF - Instituto de Ensino Superior de Fortaleza, como requisito parcial para obtenção do título de Especialista em Gerenciamento de Projetos, sob a orientação do Prof. Esp. José Flávio Gomes Fernandes. 


\section{A TECNOLOGIA DA INFORMAÇÃO NOS ESCRITÓRIOS DE ADVOCACIA}

Antônio Júnior da Silva Maia

Graduação em Análise e Desenvolvimento de Sistemas (UNIVERSIDADE ESTÁCIO DE SÁ)

Pós-Graduando em Gerenciamento de Projetos (UNICE)

\section{RESUMO}

A Tecnologia da Informação, atualmente, tem presença direta em vários tipos e ramos profissionais, e, no Direito, isso não tem sido diferente. Na organização e em modelos de atividade e de negócio, a informatização torna-se um aliado na execução de várias rotinas nesse meio. Dessa maneira, tem-se criado novos conceitos e adaptações de todo o cenário jurídico com base nas tecnologias direcionadas à advocacia que vêm se expandindo cada vez mais e tornando-se fundamental no desenvolvimento e na evolução destes negócios. Desde as repartições judiciárias até os escritórios, a inovação tecnológica já é visível e constitui vários recursos que auxiliam a criatividade e a eficiência profissional, o que gera um diferencial no mercado jurídico tanto na qualidade e agilidade dos serviços quanto na fidelização destes clientes. São inúmeros os desafios neste processo, e, portanto, entende-se que deve haver uma integração da tecnologia aos negócios jurídicos. Ademais, é fato que todo o conhecimento de conteúdos relacionados às áreas jurídicas, tais como leis, normas e diretrizes, é essencial, e esses conteúdos se relacionam aos conceitos de gestão, de comportamentos humanos e pessoais e de tecnologia, que servem de contribuição para se obter um diferencial jurídico.

Palavras-chave: Tecnologia da Informação; Escritórios; Advocacia; Direito.

\section{INTRODUÇÃO}

Com o aumento da complexidade e a necessidade de organização no cenário jurídico, é fato que a utilização da Tecnologia da Informação tornou-se um facilitador para a gestão. Por intermédio de softwares e ferramentas de desempenho que visam à organização, à agilidade, a uma melhor comunicação e ao maior processamento das informações, é possível obter feedbacks efetivos, como o aprimoramento das leis correlacionadas. Com esta nova sistemática, tem sido necessária a adaptação dos operadores do Direto no avanço do uso de softwares. 
Em conjunto com os profissionais que detêm o conhecimento tecnológico, os escritórios de advocacia, atualmente, adaptam-se a estes sistemas inteligentes e formam, consequentemente, um novo modelo de negócio. A evolução da tecnologia no Direito, hoje em dia, não deixa de ser uma realidade, seja para um escritório modesto, médio ou de grande porte. Neste sentido, o uso da tecnologia objetiva obter melhoria das atividades internas e agilidade na resolução das leituras processuais e na organização dos dados.

É relevante ressaltar a importância de uma integração contínua de pessoas mediante a inclusão digital, onde, por intermédio de treinamentos, capacitação e integração, todo esse sentido funciona como um segmento ativo que fornece à ciência do Direito respostas e iterações relevantes, além de rever critérios e comportamentos que permitem o aprimoramento do âmbito jurídico.

\section{ESCRITÓRIOS DE ADVOCACIA}

Os escritórios de advocacia exercem atividades que objetivam manter e aplicar a ordem jurídica aos casos concretos, defendendo, assim, o estado de Direito. É de interesse daqueles envolvidos na esfera judiciária estarem em acordo com as normas. O princípio no exercício dessa profissão tem forte influência empírica, e todo o conceito deve ser científico e partir de uma doutrina em respeito ao regime jurídico, à ética e à preservação da ordem.

Antes da inclusão digital, a Advocacia continha restrições no quesito tecnológico. Dessa forma, com o surgimento desses projetos como facilitadores, ocorreram melhorias nas rotinas desse ramo que, incorporadas no dia a dia, atendem ao exercício da profissão. Logo, a tecnologia deve ser tratada enquanto uma aliada que contribui com a geração de todo o conhecimento da justiça.

De acordo com a Ordem dos Advogados do Brasil - OAB, ${ }^{1}$ o país conta com mais de 1.220 milhões de advogados, que, em sua maioria, possuem escritórios modestos. As organizações advocatícias devem estar sintetizadas ao conceito

1 Ordem dos Advogados do Brasil. Institucional / Quadro de Advogados. Disponível em: https://www.oab.org.br/institucionalconselhofederal/quadroadvogados. Acessado em: 28/jul/2019. 
tecnológico que instaura toda uma estrutura interna informatizada, necessária para o acesso das plataformas digitais dos tribunais.

Vale considerar que, na execução da sua rotina, os advogados utilizam os sistemas para obterem toda a composição processual, a análise e as respostas necessárias para o encerramento de todo o fluxo. É preciso destacar que, nesse procedimento, deve haver a assinatura digital, que é uma autenticação previamente cadastrada, que serve para que o sistema confirme as informações do profissional, o que mantém a integridade e a segurança dos dados.

Termos computacionais, como cloud computing e robôs advogados, hoje são comuns, e estes novos conceitos acarretam em uma grande transformação nos escritórios, sejam de grande, médio ou pequeno porte, pois tornou-se indispensável o seu funcionamento com base nestas ferramentas digitais.

\subsection{Inovação na Advocacia}

A prestação dos serviços jurídicos, atualmente, conta com inúmeros recursos em tecnologia que automatizam rotinas com uma maior agilidade. Atividades como o controle de processos e a redação de documentos jurídicos contavam, antigamente, com um procedimento bastante pessoal, onde, muitas vezes, o profissional centralizava o serviço. Este modelo ficou conhecido como advocacia 1.0. Apesar de o trabalho executado ter organização e excelência, geralmente era bastante caro, lento e restrito, pois o mercado era bem reduzido e o trabalho era feito praticamente de forma manual, concentrando-se totalmente na figura do advogado e fazendo com que as ações ficassem limitadas.

Com o surgimento da advocacia 2.0, houve o desenvolvimento em todo um contexto estrutural com base em escritórios. Em outras palavras, a atuação foi crescendo em nível nacional e as vertentes do negócio tiveram uma expansão envolvendo várias atividades. Os escritórios, além dos profissionais de advocacia, passaram a utilizar secretárias, estagiários, dentre outros tipos de trabalhadores, formando, assim, toda uma estrutura empresarial. Tal modelo estendeu-se, principalmente, dos anos 1960 até o ano 2000 e envolveu grandes demandas de 
massa e aumento da quantidade de serviços jurídicos, em virtude da volta da democracia, do neoliberalismo, das privatizações, da expansão territorial das grandes empresas e da relevante utilização da tecnologia no dia a dia dos escritórios. Houve um aumento considerável na quantidade dos serviços, pois, no Brasil, acontecia uma reestruturação democrática com a reformulação da Constituição de 1988 e a criação dos juizados especiais. Iniciou-se o uso dos computadores, dos editores de texto e das planilhas eletrônicas, o que facilitou a execução dos serviços e propiciou a redução do tempo de atendimento ao cliente. Nesta transição ainda, a tecnologia continha suas limitações, porém havia a praticidade ao automatizar as atividades desempenhadas.

A partir dos anos 2000, iniciou-se a advocacia 3.0, induzida pela globalização, que encurtou ainda mais as distâncias entre as nações e permitiu o fácil acesso a grande parte das regiões do planeta. Nesse cenário, os indivíduos podem concorrer e colaborar independentemente das distâncias geográficas, porque, facilmente, podem estar presentes em todos os lugares onde haja internet.

Uma das principais mudanças adotadas pela advocacia 3.0 foi a implantação de um modelo direcionado para a gestão. As atividades que antes eram centradas passaram, neste momento, a serem integradas aos setores e colaboradores, e os escritórios apostavam em um sistema menos hierárquico, mais colaborativo e voltado à experiência do cliente.

Este modelo desenvolveu-se com foco em pessoas integradas à tecnologia. Nele, utilizam-se softwares jurídicos, gerenciamento de documentos, gestão de processos, organização financeira e uma variedade de sistemas modernos. A atuação antes continha empecilhos territoriais, e, nesse modelo, não há mais limitações, haja vista o uso da internet. Uma consequência disso foi que o mercado se tornou altamente competitivo. Outra vantagem foi quanto à valorização dos talentos e das habilidades em atendimento, gerência, estatística e liderança. A advocacia 3.0 contém a automação de rotinas e um maior cuidado na experiência do cliente, o que foi possibilitado pela utilização de softwares que suprem necessidades básicas, como, por exemplo, os retornos periódicos aos clientes. 
Por fim, houve a evolução para a advocacia 4.0, na qual, de fato, há uma utilização considerável de conceitos como big data, robôs, inteligência artificial e computação na nuvem. Na dinâmica da sociedade contemporânea, espera-se do advogado um espírito empreendedor e uma visão crítica como aproveitamento não apenas das oportunidades da advocacia tradicional, mas também de seu pensamento crítico. Ele também deve integrar-se totalmente às mudanças do mercado e do seu ramo profissional a partir de diversas perspectivas.

\subsection{Formação do Profissional diante a Tecnologia}

Entender que a tecnologia é um agente de transformação em qualquer circunstância na área do Direito, entre advogados e clientes, é uma abordagem para antecipar as mudanças. Com isso, é necessário que haja capacitações direcionadas para o entendimento dessas ferramentas tecnológicas. Tal percepção já foi notada em alguns países. No ano de 2012, as Associações de Advogados norte-americanas desenvolveram novos conceitos orientando os profissionais sobre a importância das inovações, pois o intuito é integrá-los aos avanços tecnológicos.

No Brasil, por mediação do Ministério da Educação e Cultura - MEC, foram regulamentadas novas diretrizes com referência à grade curricular de todos os cursos jurídicos, listadas na Resolução $n . .5$, de 17 de dezembro de 2018. Neste documento, o artigo $4^{\circ}$, nos incisos XI e XII, estabelecem que:

XI - O profissional da área jurídica deve compreender o impacto das novas tecnologias na área jurídica;

XII - O profissional da área jurídica deve possuir o domínio de tecnologias e métodos para permanente compreensão e aplicação do Direito;

Deve-se ressaltar que, no intuito de acompanhar o entendimento acerca das inovações tecnológicas, o MEC, mediante a Resolução $n .0$ 5, enfatiza que as instituições de ensino devem conter uma estrutura informatizada para executarem cursos neste segmento, com todas as condições necessárias e equipamentos adequados, para, assim, possibilitar o apoio e o entendimento destas novas tecnologias. 
Uma nova abordagem do conhecimento em tecnologia resultou em um novo mindset, o qual é definido por um modelo mental predominante que determina ações direcionadas que colocam o advogado em uma situação de contínua curiosidade como forma de estratégia em sua área de atuação.

\section{A INFORMATIZAÇÃO DO JUDICIÁRIO}

Como forma de desburocratizar, acelerar processos e atender efetivamente todos os cidadãos, foi criada a Emenda Constitucional 45, no ano de 2004, e, consequentemente, foi criado o Conselho Nacional de Justiça - CNJ. Este conselho visa a colocar boas práticas e técnicas para acelerar as resoluções processuais e aprimorar o planejamento estratégico, a modernização e a gestão administrativa dos tribunais para se ter um controle disciplinar e correcional.

Neste contexto, após os fatos expostos, em 2006, no Brasil, é desenvolvido o processo digital, que consiste no registro e na disponibilização dos trâmites processuais por intermédio da internet. Desde então, é realizada uma prática digital com o uso de recursos tecnológicos. Logo, com estes novos moldes, mesmo de forma lenta, porém progressiva, o processo eletrônico já é uma realidade em vários estados brasileiros.

O sistema Judiciário brasileiro tem passado por grandes transformações com a inclusão digital mediante o portal do CNJ, que centraliza a abertura dos processos eletrônicos e engloba os fóruns virtuais, o acesso às informações da justiça e a solicitação de serviços. Esta modernização tem o escopo de introduzir e efetivar o conhecimento do Direito aos cidadãos, ampliando, assim, o acesso deles à Justiça e gerando melhorias nas estruturas governamentais. Esta adaptação está em constante evolução e acontece em todo o contexto social, e isso impacta diretamente a comunicação dos cidadãos com as instituições.

A criação da Lei $n .$. 11.419/2006 determinou um novo procedimento de informatização dos processos judiciais, e isso gerou uma transformação jurídica, gerando uma evolução dos serviços no Judiciário. O uso da internet é primordial nos 
novos moldes, e, no Brasil, as operadoras de telecomunicações ainda estão evoluindo para atender à demanda.

O CNJ, integrado ao que se denomina de Reforma do Judiciário, é responsável pelas automações tecnológicas e busca total transparência administrativa e processual nas prestações de contas e na gestão. Dessa forma, tal órgão integra a melhor comunicação com os operadores de direito, coordena as ações a serem cumpridas pelos Tribunais e, também, é responsável por gerenciar a tecnologia em todas as unidades judiciais.

Com essas atividades coordenadas pelo CNJ, surge também uma adaptação da história do Direito e a criação do processo digital. O processo digital consiste em um sistema totalmente integrado que permite o processamento de todas as ações judiciais de forma virtual, ou seja, on-line, dispensando, dessa maneira, o uso do papel, e que tramita com maior agilidade e segurança as informações processuais. Para todo este funcionamento, é necessário haver toda uma infraestrutura computacional, que consiste na utilização da internet nos tribunais e no uso de computadores, e, por conseguinte, a capacitação de pessoas quanto à nova rotina informatizada e a adaptação de todos os profissionais envolvidos, como juízes, promotores, advogados, dentre outros.

Por intermédio do CNJ, foi criado o sistema de Processo Judicial Eletrônico - PJE, desenvolvido com a parceria dos tribunais e a OAB. O objetivo é permitir a prática de todos os atos processuais e o seu acompanhamento. O CNJ pretende reunir esforços dos tribunais brasileiros e adotar uma solução única e gratuita para os próprios tribunais, atendendo, dessa forma, a requisitos importantes, como segurança, interoperabilidade e diminuição de gastos com a elaboração e a aquisição de softwares, o que permite a integração de valores financeiros e pessoais em atividades mais dirigidas à finalidade do Judiciário.

A composição deste processo eletrônico contém alguns elementos digitais indispensáveis, como documento eletrônico, peticionamento eletrônico, recibo eletrônico, assinatura eletrônica, assinatura digital e certificado digital, todos eles integrados no meio digital. Resultados positivos foram obtidos com a implantação 
desse processo, dentre os quais estão a economia de tempo e a de recursos materiais, como o papel, por exemplo. Além da economia financeira, isso gera também uma responsabilidade social e uma maior agilidade na tramitação dos processos, se comparados aos convencionais, pois reduz o tempo de atendimento, minimiza as filas para o atendimento e o recebimento das demandas e ocasiona a diminuição no espaço físico tanto para a instalação de novos órgãos do Poder Judiciário quanto para o arquivamento desses documentos. Este pacote integrado é um meio que pode garantir a celeridade processual. Os resultados mostram-se positivos e observa-se que é possível um processo digital ser distribuído e ter uma tramitação diligente, respeitando, dessa maneira, os princípios constitucionais e infraconstitucionais.

Desde 1981, há adaptações das leis no Estado brasileiro com referência à tecnologia e ao uso de meios digitais no âmbito legal. No entanto, com a implantação do processo digital, a abordagem perante a administração e a organização do trabalho nos escritórios fez com que se adotassem tais práticas, as quais se tornaram cotidianas.

A utilização de softwares em gestão, workflow, projetos, automação de documentos, jurimetria, previsão de resultados, análise preditiva de comportamento do Judiciário, gestão de riscos legais, dentre outros elementos, são exemplos de uma realidade nos escritórios. Entretanto, deve-se entender que este novo paradigma é também estudo de casos concretos que pressupõe o raciocínio analítico no encontro dessas soluções diferenciadas.

\section{LAWTECHS E LEGALTECHS}

De acordo com uma pesquisa realizada em julho de 2018 pela Associação Brasileira de Lawtechs \& Legaltechs - AB2L, ${ }^{2}$ em torno de 38 empresas no Brasil trabalham com serviços direcionados ao setor jurídico. Ademais, $37 \%$ dos advogados informaram que o escritório ou a empresa onde trabalham não utiliza

2 AB2L - Associação Brasileira de Lawtechs e Legaltechs. O que são as legaltechs no Brasil?. Disponível em: https://www.ab2l.org.br/o-que-sao-as-legaltechs-no-brasil-2/. Acessado em: 08/ago/2019. (2) 
ferramentas tecnológicas para o desenvolvimento de suas atividades, e $88 \%$ dos profissionais alegaram que o local onde trabalham pretende utilizar soluções de lawtechs em um futuro próximo como forma de auxílio nas demandas internas. A aludida pesquisa revela igualmente que cerca de $95 \%$ dos escritórios de advocacia estão abertos às inovações para a solução de seus problemas e que $62 \%$ deles já estão procurando por serviços customizados neste quesito.

Perante este cenário, surge um novo tipo de empresa: as legaltechs. Elas são startups direcionadas para todo o negócio jurídico. Tais empresas desenvolvem uma estrutura de sistemas, processos e atividades e contêm a premissa da utilização da tecnologia para a facilitação da rotina jurídica. Em consequência disso, foram criadas as lawtechs, as quais contêm soluções focadas no público final, ou seja, os clientes dessas organizações advocatícias.

Na visão do advogado, isso independente da sofisticação a ser adotada, porquanto resulta por parte deste um maior direcionamento à intelectualidade. Há um aumento da produtividade e da eficiência com essas resoluções, e isso, logo, despertou a atenção dos departamentos jurídicos.

Na concepção de Antônio Maia, o fundador da Tikal Tech:

A tecnologia é um grande agente na democratização dos serviços jurídicos e busca tornar acessível para todos. É mais um ganho social, porque quanto mais advogados forem estruturados em plataformas online, por exemplo, mais a sociedade tem a ganhar. ${ }^{3}$

Com a implantação dessas soluções jurídicas, poderá haver inúmeras melhorias para as empresas, tanto em relação à otimização do tempo no exercício do advogado, quanto ao acesso à justiça, tornando-o menos burocrático.

Enfatizando este aspecto, de acordo com Bruno Feigelson, presidente da AB2L, a tecnologia permite uma maior transparência das informações e do próprio

3 AB2L - Associação Brasileira de Lawtechs e Legaltechs. AB2LNAMIDIA Lawtech: o que é e como está o mercado para essas startups?. Disponível em: https://www.ab2l.org.br/lawtech-o-que-e-e-comoesta-o-mercado-para-essas-startups/. Acessado em: 08/ago/2019. (1) 
negócio de maneira mais organizada. "Eu só enxergo vantagens em usar tecnologia no setor jurídico, ela tem total transparência e entrega um valor imenso". 4

É bastante significativo que o benefício do uso das tecnologias refletese em um diferencial competitivo aos negócios jurídicos. Analisando os pontos positivos, deve-se destacar, além de organização, o lucro como resultado final do investimento em sistemas automatizados.

Com estes fatores, pode-se agilizar processos, havendo, assim, a redução de tempo e a diminuição de erros comuns, caso o serviço seja feito de forma manual. Com esta mitigação, é possível haver uma total transparência nos resultados, o que garante a confiabilidade e a organização.

\subsection{A Automação para a Organização}

A palavra automação vem do latim e significa mover-se por si, variante de automatização. Consiste no ato de tornar automático uma ou várias atividades usando a tecnologia, mediante o uso de softwares e ferramentas que operam de modo sincronizado para facilitar o que antes era feito manualmente.

Algumas rotinas suscetíveis à automatização para um profissional individual, equipe jurídica ou organização são as seguintes: ${ }^{5}$

- Procurações;

- Contratos de honorários, adesão de clientes, compra, venda de bens ou serviços;

- Petições iniciais, teses tributárias e benefícios previdenciários;

- Ações de despejo, cobrança, busca e apreensão;

- Defesas padronizadas com variações conhecidas;

- Análise e recolhimento de dados jurídicos;

- Automatização de registros com informações processuais;

4 Idem. Ibidem. Disponível em https://www.ab2l.org.br/lawtech-o-que-e-e-como-esta-o-mercado-paraessas-startups/. Acessado em: 08/ago/2019. (1)

5 Enhanced Legal Intelligence. Benefícios da Tecnologia da Advocacia: o guia completo da inovação jurídica. Disponível em: http://elibot.com.br/blog/beneficios-da-tecnologia-na-advocacia/. Acessado em: 23/jun/2019. 
- Acompanhamento de todo o ciclo da vida processual; e

- Automação de todos os documentos jurídicos.

\subsubsection{O Armazenamento em Nuvem}

\section{- Rede Interna}

O armazenamento em rede utiliza plataformas físicas para armazenar dados ligados diretamente a um único computador ou vários, constituindo-se, dessa maneira, em uma rede compartilhada, onde os computadores estão conectados e possuem acesso às informações de um único servidor.

\section{- Nuvem}

O armazenamento em nuvem consiste em guardar informações em empresas contratadas, chamadas de provedores on-line, onde ficam guardadas em servidores particulares e podem ser acessadas mediante autenticação por intermédio de senha. Para integridade delas, é definido o acesso restrito individual ou coletivo, o qual tem embasamento nos contratos de serviços.

Neste contexto, inúmeras vantagens são perceptíveis para as empresas que contratam esses serviços, pois não há a necessidade de aparelhos externos ou físicos, e, com isso, gera-se uma economia em vários aspectos, como em equipamentos, energia, arquivos, dentre outros. Além da segurança, neste tipo de prática, outro ganho é quanto à facilidade para a busca de informações, pois, conectado à internet, o usuário possui acesso de forma global e sem restrições, o que favorece todo o trabalho.

\section{- Workflow}

A organização de tarefas é algo que se deve levar em consideração nos escritórios e departamentos jurídicos, haja vista a necessidade de organizar, de ser eficiente e econômico e de ter controle. Ao executar as tarefas, é definido cada processo de trabalho e é delimitado o papel de cada participante da equipe com sua 
atribuição, alcance e controle definidos, e seus integrantes são devidamente vinculados a outros participantes. Tudo é devidamente documentado e fica disposto como uma norma padronizada.

Um workflow bem enquadrado permite que cada atividade possa ser rastreada e que cada trâmite e/ou procedimento possa ser identificado. São identificados metricamente os gargalos em todo o processo. Com isso, é possível realizar o investimento correto e ter a total precisão nos resultados, caso haja possíveis ineficiências estruturais. A rastreabilidade permite também a geração de relatórios estratégicos para o negócio, os chamados Business Intelligence - BI. Estas informações geradas devem ser inseridas em sistemas com a geração de dashboards e/ou relatórios para se obter uma visão estratégica.

\section{- Inteligência Artificial}

A Inteligência Artificial, conhecida pela sigla IA, é uma ciência que atua no desenvolvimento de inteligência, cujos os efeitos são semelhantes a uma atividade

humana com a aplicação em máquinas e softwares. Pode-se afirmar que é responsável por criar padrões inteligentes que percebem, raciocinam e resolvem problemas com o uso de técnicas de programação.

Várias áreas da ciência englobam a estruturação de informações, como o machine learning, o deep learning, dentre outras. Tal uso é feito mediante algoritmos matemáticos que, além do desenvolvimento, processamento e cognição semântica, colaboram na interpretação de mensagens, textos e imagens e fazem com que os sistemas contenham raciocínios lógicos, cujos efeitos estão cada vez mais próximos ao raciocínio humano. A utilização da Inteligência Artificial tem um futuro promissor e continua evoluindo em diversas áreas e, inclusive, na advocacia.

Os setores jurídicos já utilizam sistemas de Inteligência Artificial definidos como robôs. Eles captam as informações dos tribunais, realizam monitoramentos, reduzem erros e colaboram com a conclusão de diversos processos. Isso influencia diretamente em atividades processuais e manuais, o que permite que os profissionais apliquem mais tempo em atividades gerenciais. 
Segundo uma pesquisa realizada pela Associação Brasileira de LawTechs e LegalTechs - AB2L, ${ }^{6}$ a maior demanda de advogados e escritórios são por tecnologias que organizam as atividades tradicionais. Dentre essas demandas, estão o monitoramento legislativo, o clipping de notícias, a jurisprudência e o acompanhamento de ações.

\section{FIGURA 1. DEMANDAS DAS EMPRESAS}

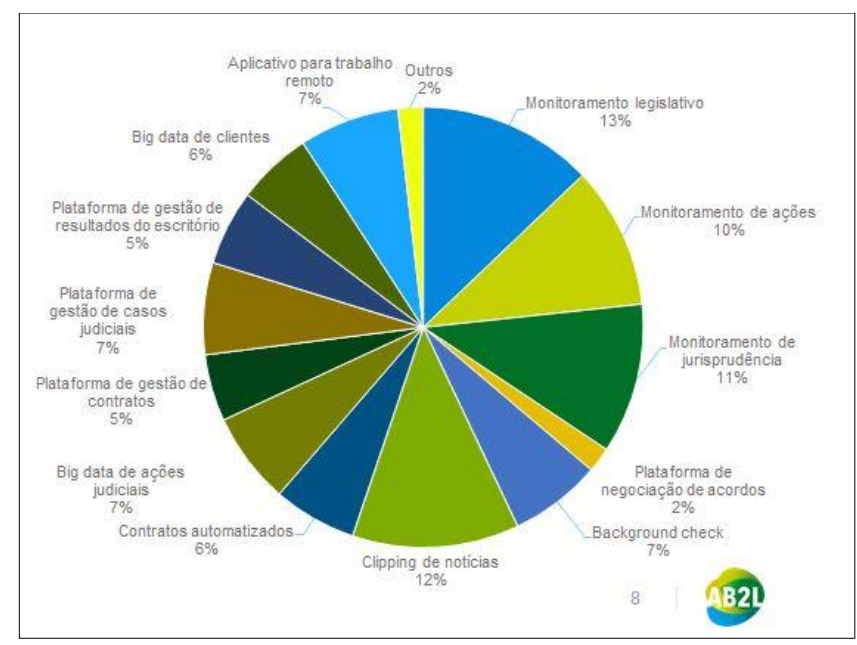

Fonte: STARTUPI - AB2L apresenta primeira pesquisa nacional sobre o cenário de lawtechs $e$ legaltechs. Disponível em: https://startupi.com.br/2017/07/ab2l-apresenta-primeirapesquisa-nacional-sobre-o-cenario-de-lawtechs-e-legaltechs/. Acessado em 08/Ago/2019.

A mesma pesquisa informa que uma grande parte desses profissionais não possui o conhecimento de que há no mercado essas soluções disruptivas, como, por exemplo, os robôs inteligentes.

Deve-se elucidar que a IA não deverá substituir o humano e que, muito menos, ela se trata de uma ameaça para o Direito. Ela é diretamente ligada às necessidades jurídicas e complementa as rotinas e o modelo jurídico. Ademais, é considerada um diferencial no alcance de resultados rápidos e positivos que proporcionam qualidade e lucratividade. O fato é que todo o âmbito jurídico está em constante evolução digital e avança a cada dia, melhorando as suas tecnologias e com o escopo de alcançar um diferencial no mercado.

6 STARTUPI - AB2L apresenta primeira pesquisa nacional sobre o cenário de lawtechs e legaltechs. Disponível em: https://startupi.com.br/2017/07/ab2l-apresenta-primeira-pesquisa-nacional-sobre-ocenario-de-lawtechs-e-legaltechs/. Acessado em: 08/ago/2019. 


\section{- Jurimetria}

Para o advogado entender as necessidades dos clientes e prever padrões, comportamentos e tendências, é aplicada a jurimetria, a qual consiste em entender e compreender processos e fatos jurídicos partindo de modelos estatísticos e relacionar padrões decisórios diante das informações da justiça.

A jurimetria é a estatística aplicada ao direito em uma análise simples e direta e tem sido utilizada em conjunto com softwares jurídicos em um molde para tentar prever resultados e oferecer probabilidades e valores envolvidos nas análises. Por esse motivo, trata-se de uma questão estatística.

\section{- Blockchain}

O blockchain consiste em um conjunto de tecnologias com arquitetura distribuída e descentralizada, que registra todas as tramitações processuais. Possui um banco de dados compartilhado que mantém uma lista crescente de registros das transações envolvendo ativos ou dispositivos digitais.

As informações podem ser verificadas e auditadas. Esta tecnologia tem atuação em vários fronts como forma de condução dos processos e agilização dos prazos para os profissionais e cuida de toda a segurança jurídica.

As técnicas de blockchain podem ser aplicadas no Direito em:

- Registro de provas de autoria;

- Registro de dados para escritórios e empresas;

- Autenticação de documentos; e

- Contratos eletrônicos.

\section{- Gestão de Documentos}

Todo material resultante das informações jurídicas gera um grande volume de documentos. Logo, é crucial o arquivamento adequado dessas 
informações. Nos processos digitais e nas rotinas jurídicas, é formada toda uma composição de materiais em que é necessária a disciplina no manejo e para a garantia da administração documental.

A gestão de documentos objetiva organizar toda a produção desses documentos e deve, como qualquer boa prática, seguir modelos padronizados para este controle. A implantação desses sistemas eletrônicos tem o intuito de gerenciar os arquivos gerados e viabiliza a economia de tempo e espaço. As empresas de softwares já possuem sistemas para atender este quesito, visto que, além de otimizar toda a gestão documental, potencializam o fluxo e o registro permanente dessas informações.

O fluxo desse gerenciamento de documentos consiste em: captura, tramitação, utilização e arquivamento, até a sua destinação final, que é a eliminação ou o recolhimento para registro permanente mediante o uso de um único sistema e a integração dele com outros existentes.

Compreende-se que, no Brasil, os escritórios advocatícios podem ser de médio ou pequeno porte e, em sua maioria, são do tipo sociedades simples. Mediante todos os conceitos tecnológicos apresentados, cabe a pergunta: "Como e quando $o$ escritório de advocacia deve investir em tecnologia?".

Em uma visão contextual, ao montar um plano de negócio neste quesito, é possível surgir uma oportunidade para o ingresso rápido no mercado e com um investimento inicial relativamente baixo. Logo, existem algumas restrições, que são financeiras e devem ser analisadas antes da execução e expansão desse tipo de atividade.

Devem estar inclusas neste modelo, enquanto forma de estratégia, ações como enxergar, orçar e fazer caber no orçamento o investimento direto em tecnologia, pois este cenário já é bastante presente. A realidade atual, inclusive, já tem referências e resultados quanto ao desempenho e à melhor resolução de todas as rotinas administrativas, tornando o negócio cada vez mais competitivo, e o 
processo de transformação digital faz com que aconteça uma mudança de mindset em todos os profissionais envolvidos.

\section{CONCLUSÃO}

Portanto, o profissional de advocacia deve usar a tecnologia a seu favor. Logo, ele precisa se preparar para um mercado cada vez mais competitivo. Atualmente, muitas empresas de softwares desenvolvem sistemas para atuar em parceria com estes profissionais e/ou escritórios com o propósito de facilitar o trabalho, e isso, além de dar uma visão geral empreendedora, organizacional e estratégica, torna o profissional diferenciado. Este destaque permite ao advogado uma atuação mais gerencial e com foco nos negócios e resultados.

No cenário jurídico, conclui-se que a tecnologia também contribui com a redução da burocracia e torna o acesso mais rápido e simples. Para os clientes, ela enfatiza relações fluídas e instantâneas.

O advogado deve possuir um olhar diferenciado e a compreensão de como a tecnologia impacta a advocacia. Otimizar a gestão mediante estes recursos, que são os softwares jurídicos, muitas vezes, atende diretamente os clientes com referência à qualidade, agilidade e eficácia. Um pacote de três elementos, que são a gestão, a tecnologia e a inovação, possui um grande potencial na transformação do modelo estratégico de uma organização advocatícia.

\section{FONTES ON-LINE:}

AB2L - Associação Brasileira de Lawtechs e Legaltechs. AB2LNAMIDIA Lawtech: o que é e como está o mercado para essas startups?. Disponível em: https://www.ab2l.org.br/o-que-sao-as-legaltechs-no-brasil-2/. Acessado em: 08/ago/2019. (1)

AB2L - Associação Brasileira de Lawtechs e Legaltechs. O que são as legaltechs no Brasil?. Disponível em: https://www.ab2l.org.br/o-que-sao-as-legaltechs-no-brasil-2/. Acessado em: 08/ago/2019. (2) 
BACELAR, Lígia Maria do Nascimento. A gestão documental em escritórios de advocacia como busca pelo aprimoramento e controle de material produzido em decorrência das atividades pertinentes ao setor jurídico. Disponível em: https://www.editorarealize.com.br/revistas/joinbr/trabalhos/TRABALHO_EV081_MD4 _SA58_ID2052_15092017201704.pdf. Acessado em: 03/jul/2019.

CNJ - Conselho Nacional de Justiça - Processo Judicial Eletrônico. Disponível em: https://www.cnj.jus.br/tecnologia-da-informacao/processo-judicial-eletronico-pje. Acessado em: 07/jun/2019.

ENHANCED LEGAL INTELLIGENCE - Benefícios da Tecnologia da Advocacia: o guia completo da inovação jurídica. Disponível em: http://elibot.com.br/blog/beneficios-da-tecnologia-na-advocacia/. Acessado em: 23/jun/2019.

HINO, Marcia Regina Martelozo Cassitas e CUNHA, Maria Alexandra. A Tecnologia da Prática dos Escritórios de Advocacia no Brasil. Disponível em: https://www.academia.edu/4572733/A_Tecnologia_na_Pr\%C3\%A1tica_dos_Escrit\% C3\%B3rios_de_Advocacia_no_Brasil. Acessado em: 08/jul/2019.

INFOMONEY - Primeiro "robô advogado" do Brasil é lançado por empresas brasileira. Disponível em: https://www.infomoney.com.br/negocios/inovacao/noticia/ 6757258/primeiro-robo-advogado-brasil-lancado-por-empresa-brasileira-conheca. Acessado em: 15/jun/2019.

JUS.COM.BR - A Emenda Constitucional n. 045 e a Reforma do Judiciário. Disponível em: https://jus.com.br/artigos/7465/a-emenda-constitucional-n-45-e-a-reforma-dojudiciario. Acessado em: 10/set/2019.

JUSBRASIL - Advogado 3.0 - A jovem advocacia nunca esteve tão forte. Disponível em: https://jusbrasil.jusbrasil.com.br/artigos/607711275/advogado-30. Acessado em: 15/jun/2019.

- O papel da tecnologia na gestão de escritório de advocacia. Disponível em: https://sajadv.jusbrasil.com.br/artigos/399617899/o-papel-da-tecnologia-na-ges taode-escritorio-de-advocacia. Acessado em: 28/jun/2019.

MATOS, Gabriela da Costa. $A$ advocacia em tempos digitais: uma análise da prática advocatícia face às consequências do acesso tecnológico. Disponível em: http://ri.ucsal.br:8080/jspui/bitstream/prefix/758/1/TCCGABRIELAMATOS.pdf.

Acessado em: 15/abr/2019.

ORDEM DOS ADVOGADOS DO BRASIL. Conselho Federal. Processo Judicial Eletrônico. Disponível em: https://emporiododireito.com.br/wp-content/uploads/ 2015/04/Processo-judicial-eletr\%C3\%B4nico.pdf. Acessado em: 15/abr/2019.

Institucional / Quadro de Advogados. Disponível em: https://www.oab.org.br/institucionalconselhofederal/quadroadvogados. Acessado em: 28/jul/2019. 
PEREIRA, Maria Neuma. A Tecnologia Aplicada como Garantia da Celeridade Processual. Revista Ciências Jurídicas e Sociais - UNG - SER. Disponível em: http://revistas.ung.br/index.php/cienciasjuridicasesociais/article/view/918/898. Acessado em: 15/abr/2019.

PREAMBULO. TECNOLOGIA EM GESTÃO JURÍDICA. Tecnologia e o futuro da advocacia. Disponível em: https://www.preambulo.com.br/tecnologia-e-o-futuro-daadvocacia/. Acessado em: 25/jun/2019.

STARTUPI - AB2L apresenta primeira pesquisa nacional sobre o cenário de lawtechs e legaltechs. Disponível em: https://startupi.com.br/2017/07/ab2l-apresenta-primeirapesquisa-nacional-sobre-o-cenario-de-lawtechs-e-legaltechs/. Acessado em: 08/ago/2019. 